\title{
BALANCES Y PERSPECTIVAS DEL PERITAJE ANTROPOLÓGICO: RECONOCER O BORRAR LA DIFERENCIA CULTURAL
}

\author{
Artemia Fabre Zarandona \\ artemia_fabre@yahoo.com \\ Diálogo y movimiento, A. C.
}

\section{RESUMEN}

Reflexionar y discutir en general sobre los actuales cambios constitucionales en términos de los usos de los instrumentos jurídicos legales, por parte no solo de los operadores de justicia sino también de los mismos individuos y colectivos indígenas, se vuelve una tarea fundamental en nuestro quehacer. En específico para el caso que nos ocupa de los peritajes antropológicos es necesario observar los avances y retrocesos en materia de los derechos indígenas, y fundamentalmente conocer cambios en la cultura político-jurídica que estas modificaciones constitucionales hayan generado o no, en especial en los operadores de justicia, teniendo en cuenta si este instrumento es o no pertinente en la procuración e impartición de justicia. De igual forma, es pertinente preguntarnos si podemos hablar del peritaje como un instrumento que incluye la diversidad cultural en los aparatos de justicia $\mathrm{y}$, por ende, que dé una respuesta edificante para los individuos y grupos con culturas diferentes en México.

Palabras clave: reconocimiento de los pueblos indígenas, peritaje antropológico, justicia y equidad. 


\section{SUMMARY}

Reflecting on and generally discussing current constitutional changes in terms of uses of legal juridical instruments on the part not only of the operators of justice but also of indigenous individuals and collectives themselves has become a fundamental task within our daily work. Specifically for the case at hand regarding anthropological investigations, it is necessary not only to observe the progress made and the setbacks encountered in indigenous rights matters, but fundamentally to identify changes in the political-juridical culture that these constitutional modifications have or have not generated, especially in the operators of justice, and whether or not this instrument is pertinent in the procurement and enforcement of justice. In the same way, it is pertinent to ask ourselves whether we can talk of expert investigation as an instrument that includes cultural diversity in the justice apparatus and therefore that provides an edifying response for individuals and groups from different cultures in Mexico.

Key words: recognition of indigenous peoples, anthropological investigation, justice and equity. 


\section{INTRODUCCIÓN}

El peritaje que habla específicamente de los individuos que pertenezcan a algún grupo étnico tiene ya 19 años $-\mathrm{y}$ los antropólogos tenemos la tendencia a llamarlo peritaje antropológico o cultural, ${ }^{1}$ su inclusión en el Código de Procedimiento Penales para el Distrito Federal, CPP, y el Código Federal de Procedimientos Penales en materia del Fuero Común para el Distrito Federal y para toda la República en materia del Fuero Federal, CFPP, se dio a partir de enero de $1991 .^{2}$ No obstante, la mayoría de los operadores de justicia no lo conocen y mucho menos tiene una idea clara de cómo utilizarlos en la defensa de individuos o pueblos indígenas. Esto es extensivo también a los miembros de organismos sociales abocados a los derechos humanos, a los sujetos indígenas y a la sociedad en general.

Debido a su poco conocimiento, como un instrumento de prueba, y que va emparejado a una no comprensión de lo que es la diversidad cultural —entendida como el reconocimiento de la existencia de culturas diversas en el seno de nuestra sociedad- $;^{3}$ genera mayor reproducción de una retórica jurídica y política. Por ello, el peritaje debiera ser un vehículo más para hacer un uso edificante que permita a los individuos y colectivos indígenas ser reconocidos en su diferencia cultural; y un instrumento de apoyo para que las sentencias más que reproducir la desigualdad social y la discriminación sean un instrumento que permita valorar y entender las acciones delictivas o no de un sujeto, tomando en cuenta su lugar y posición en una cultura determinada con una relación de paridad y de equidad. Contrario a esto, el peritaje tal cual se encuentra permite que se siga ahondando más la diferencia y la asimetría entre los individuos indígenas, y por consiguiente de sus sociedades frente a la sociedad en general.

Esto se debe, entre otras cosas, a que no existe realmente claridad en el objeto del uso del peritaje como medio de prueba, es decir, no se utiliza en aquellos casos en los que se presupone que los hechos delictivos se han realizado bajo la influencia cultural, ${ }^{4}$ sino más 
bien como una cédula de identidad, lo cual implica una trasgresión al principio jurídico de autoadscripción (cfr. Convenio 169 de la OIT), ${ }^{5}$ entre otros problemas. He aquí la primera dificultad, pues no queda claro en el artículo 220bis del Código Federal de Procedimientos Penales qué se entiende por diferencia cultural. A esto me referiré más adelante.

El peritaje debe o tiene el reto de zanjar la brecha y la complejidad que se deriva de sancionar a individuos indígenas que se encuentran muchas veces en lugares fuera de sus comunidades, o en situaciones de trasformación rápida en sus comunidades que obliga a sacar los casos a juzgados estatales o federales; además de la imbricación sociojurídica y cultural en la cual se encuentran insertos sus sistemas normativos, ${ }^{6}$ en donde sus referentes de visión de mundo no solo quedan invisibilizados sino que también quedan desdibujados y menospreciados debido al desconocimiento y lugar social que tienen en general los pueblos y comunidades indígenas; esto es, se encuentran en situaciones de vulnerabilidad social, jurídica, económica, etcétera.

El peritaje antropológico puede y debe volverse un instrumento eficaz para la construcción de una nueva relación entre los pueblos indígenas, la sociedad y el Estado, que se refleje en una vinculación concreta de esas sociedades con los aparatos de justicia estatales. De esta manera, afirmo que el peritaje es la oportunidad de realizar una práctica científica que cuestione e incida en establecer diálogos no solo interdisciplinarios sino fundamentalmente interculturales.

En esta presentación trataré de dar una visión general de lo que implica o deberían implicar los peritajes referidos a individuos o colectivos indígenas a partir de su uso edificante para que no solo sirvan como un medio más de reproducción de la asimetría social y, con ello, se preste al uso político de los instrumentos jurídicos y legales proclamados tanto en nuestra Constitución como en los códigos y leyes que nos rigen en el ámbito tanto nacional como internacional. 
Para los fines apuntados, este trabajo se encuentra dividido en:

1. Los derechos de los Pueblos Indígenas y la ubicación del peritaje en el contexto jurídico y social.

2. Función que tiene o debiera tener el peritaje llamado antropológico o cultural.

3. Problemas a dilucidar.

\section{LOS DERECHOS DE LOS PUEBLOS INDÍGENAS Y LA UBICACIÓN DEL PERITAJE EN EL CONTEXTO JURÍDICO Y SOCIAL ${ }^{7}$}

\section{EL LUGAR Y CORRELACIÓN DE FUERZAS ENTRE LOS PUEBLOS INDÍGENAS Y EL ESTADO}

La pregunta es: ¿podemos hablar de un cambio sustancial en la relación entre pueblos indígenas y la sociedad en general, o bien continuamos en formas veladas y a veces evidentemente etnocéntricas y racistas para establecer esta nueva relación de «reconocimiento»? ¿Estamos viviendo trasformaciones que realmente fomenten la inclusión de la diferencia cultural? O como dice Clavero (1997), la inserción de los pueblos indígenas sigue estando dentro de un monoconstitucionalismo que realmente no trasforma las relaciones existentes.

La relación desigual de los pueblos indígenas con el Estado y la sociedad se puede observar en los contenidos legales que constituyen el marco jurídico del Estado mexicano. De esta manera, desde la primera Constitución de 1824 hasta la de $1917,{ }^{8}$ negaron a los pueblos indígenas su existencia como pueblos y culturas diferentes a partir, aparentemente, de otorgarles derechos iguales a todos los ciudadanos en territorio nacional, producto de la propuesta del liberalismo e individualismo que forjaron la construcción de los Estados nacionales. Ambas propuestas crearon a los individuos como sujetos de derecho en la igualdad jurídica, en donde la soberanía recae en el pueblo, entendido como pueblo el conjunto de individuos iguales en derecho. En esta ficción de igualdad, se permite la existencia de la desigualdad como producto del desconocimiento de la diferencia. 
Lo anterior muestra que lo que actualmente sucede, según Ferrajoli (2002), es que bajo un modelo de indiferencia o de homologación jurídica las diferencias aparecen ignoradas de hecho y de derecho también.

En este sentido, el dilema constitucional estriba no solo en cómo se asume el concepto de igualdad/diferencia en el ordenamiento jurídico, sino también en las formas en cómo han sido incluidos o no los pueblos indígenas en ese ordenamiento jurídico; es decir, si son sujetos de derecho como pueblos y comunidades y si adquieren o no personalidad jurídica como entes de derecho público.

En un recuento sobre el reconocimiento legal de la diversidad y los derechos de los pueblos indígenas de México se puede dar cuenta de la adición incorporada en el artículo $4^{9}$ constitucional en enero 1992, y en las últimas reformas en materia indígena de 2001. Así como en el Convenio 169 de la Organización Internacional del Trabajo, OIT, de 1989, ratificado por México en 1990 y vigente desde entonces, se reconocen las características de vida sociocultural de la diversidad de grupos étnicos en el país; recientemente tenemos también la Declaración de los Derechos de los Pueblos Indígenas, de ONU en 2007, con lo cual se sienta un precedente más sobre la necesidad de crear nuevas formas de relaciones con los pueblos indígenas en todo el mundo.

Vale señalar que la reglamentación al artículo 4 nunca se realizó, lo cual dificultó establecer nuevas formas de negociación y relación con los pueblos indios. Por lo que tal reconocimiento fue más bien un discurso que un reconocimiento real a esos pueblos. Como se ha mencionado, se dio una segunda reforma constitucional en agosto de 2001, que implicó desafortunadamente un retroceso en el reconocimiento de la diversidad cultural de los pueblos indígenas ${ }^{10}$ ya que no resuelve la posibilidad de autonomía y de autodeterminación de este sector social al negarles personalidad jurídica en cuanto ente de derecho público. ${ }^{11}$ 
Sin embargo México, bajo otra perspectiva, da respuesta internacional a una demanda de incluir de mejor manera la diversidad cultural. No obstante que en el ámbito interno la respuesta desde el Estado hacia los pueblos indígenas y hacia la sociedad ${ }^{12}$ no ha sido la mejor muestra de una adecuación que lleve tanto hacia un Estado democrático y plural, como hacia una democracia cultural ${ }^{13}$ en donde realmente se dé viabilidad al pluralismo en donde todos sus miembros estén representados legalmente; en otras palabras es: «el derecho a la individuación concreta y ya no únicamente el de pertenecer a una Humanidad abstracta» (Touraine op. cit., p. 250).

De esta manera, se ha evidenciado que la correlación de fuerzas entre las relaciones del Estado y este sector social y político indígena es asimétrica, asimismo se ha visibilizado la complejidad que implica no solo el reconocimiento de los pueblos indígenas en nuestra Constitución sino también el establecimiento o no de derechos colectivos y la voluntad política de no cambiar la relación y visión que se tiene de los pueblos indígenas en el seno del Estado y, por ende, de la sociedad nacional.

Significa también un retroceso en materia de los derechos humanos de segunda, tercera y cuarta generación, ${ }^{14}$ ya que al no incluir la diversidad cultural se deja de lado la dimensión sociocultural en la que los individuos se desarrollan y crean su vida.

El reto está y siempre ha estado en asumir la diversidad y la equidad. Lo que implica dejar de lado las propuestas en abstracto y establecer acuerdos entre los diferentes integrantes sociales de cada Estado, a partir de realidades concretas.

Nos encontramos frente a la persistencia de la propuesta de un «Estado uninacional» y homogeneizador, que privilegia al individuo abstracto y niega las diferencias. Por otro lado, se mantiene una represión y discriminación hacia los individuos pertenecientes a culturas indígenas a través de negar justamente su existencia política y cultural al no reconocerles derechos colectivos ${ }^{15}$ y a continuar con una estrategia de otorgamiento desde el Estado de 
derecho y no del aceptar su existencia previa a la conformación del Estado, ${ }^{16}$ argumentando que se lacera la soberanía nacional. ${ }^{17}$ Por lo anterior, reconocer la autonomía y la autodeterminación de los pueblos indígenas se vuelve un punto no negociable bajo la perspectiva de un estado uninacional. ${ }^{18}$

Este punto es de vital importancia para poder valorar las reformas llevadas a cabo en materia indígena y entender el tejido social que asume una asimetría y una desigualdad social y jurídica al no reconocer a los pueblos indígenas como sujetos de derecho colectivo. Ello conlleva una ambigüedad jurídica cuando no se establece un instrumento vinculante que otorgue personalidad jurídica, entorpeciendo así no solo la solución de conflictos sino además toda relación con este sector social.

Por ello, cuando se habla del reconocimiento político plasmado en la Constitución sin que se establezca plenamente la personalidad jurídica mantiene la vulnerabilidad de certeza jurídica de este sector sujeto a derechos, también genera una ambigüedad en su ejercicio pleno, lo que provoca una indefensión al no contar con instrumentos vinculantes que produzcan el establecimiento de la personalidad jurídica como ente de derecho público, como ya mencioné; y, por tanto, la posibilidad de iniciar controversias jurídicas y tener un reconocimiento pleno que garantice derechos y relaciones claras con el Estado y en general con la sociedad.

Karla Pérez Portilla, hablando sobre las minorías y citando a Javier de Lucas, nos permite observar con claridad esta situación, aunque vale la pena aclarar que los pueblos indígenas no son minorías como tal.

Afirmar derechos colectivos carece de sentido cuando no se reconoce previamente la personalidad jurídica de la minoría, es decir, su reconocimiento como sujeto de derecho. Este reconocimiento es condición básica no sólo para el beneficio de derechos colectivos, sino especialmente para poder actuar autónomamente en la defensa de los mismos y en la protección de sus miembros («Por qué son relevantes las reivindicaciones jurídico-políticas de las minorías», en Lucas, Javier de (dir.), 
Derechos de las minorías en una sociedad multicultural, Consejo General del Poder Judicial, Madrid, 1999, p. 22, citado en Pérez Portilla 2001: 246).

El proyecto del Estado mexicano continúa aún hoy sobre la voluntad de desindianizar a los indios, con una perspectiva etnocéntrica y evolucionista, promoviendo la idea de que la diversidad contribuye a fomentar la desigualdad. Por lo cual las modificaciones constitucionales más que una propuesta política estatal hacia la diversidad y hacia la igualdad en la diferencia y la equidad ${ }^{19}$ son una retórica jurídico política. ${ }^{20}$

El ordenamiento constitucional en materia indígena no representa trasformaciones del orden jurídico mexicano ni la legitimización de la diversidad; no establece el reconocimiento de los pueblos indígenas como anteriores a la conformación del Estado, por lo que se requiere convalidar esos derechos, a través del orden constitucional.

Desde la perspectiva de Kymlicka (1996) implicaría el reconocimiento de una ciudadanía diferenciada por grupos sociales, sin constituir esto una sociedad separada; dicho con otro lenguaje, es hablar de autonomía, ${ }^{21}$ como en el caso de España o Canadá.

La existencia de los pueblos y comunidades indígenas no depende de su reconocimiento jurídico, ellos han existido y han logrado a través de una gama diversa de formas de organización y de vinculación con el Estado y la sociedad en general sobrevivir y trasformarse. El reconocimiento político y jurídico es una necesidad de entrar en el ámbito político y jurídico desde una perspectiva de reivindicación y aceptar las nuevas reglas del juego sociopolítico que se han establecido en la esfera de lo jurídico a través, también, de la reivindicación internacional sobre derechos humanos, por ello la búsqueda de un reconocimiento político pleno seguirá en la agenda nacional a través de los movimientos indígenas y movimientos sociales que requieran mayor trasparencia con el Estado. 
Podemos decir que el movimiento indígena y los movimientos sociales en general han logrado llevar a cabo modificaciones constitucionales que permiten la entrada de la diversidad cultural, sexual, religiosa, étnica, aunque no de las formas más idóneas hacia la construcción de una sociedad plural ${ }^{22}$ es decir, en igualdad de circunstancias jurídicas, a través de la equidad, se sigue bajo una forma de homogenización e invisibilización de derechos plenos a la diferencia.

Siguiendo a Ferrajoli (2002), él nos dice que si en cambio se asume la igualdad como una norma y la diferencia como un hecho corresponde establecer en la normativa jurídica mecanismos de observación y de sanción para garantizar y respetar a los diferentes como iguales. Precisamente las diferencias —de sexo, religión, cultura, etnia, entre otras - son las que deben ser tuteladas, respetadas y garantizadas, para establecer plenamente el principio de igualdad y garantizar justamente los derechos de los diferentes, que generalmente se encuentran en situaciones de vulnerabilidad y de indefensión jurídica. Como nos dice el mismo autor: «en obsequio al principio de igualdad. Y entonces no tiene sentido contraponer "igualdad" a "diferencias". Y si una "diferencia" ... resulta de hecho ignorada o discriminada, ello no quiere decir que la igualdad es "contradicha", sino simplemente que es violada» (Ferrajoli op. cit, pp. 79-80).

Para el caso de los pueblos indígenas sucede lo mismo desde esta perspectiva que he señalado. Los pueblos indígenas son sujetos que pertenecen a otros sistemas culturales, ${ }^{23}$ no comparten las mismas creencias y valores, por lo que la igualdad de condiciones ${ }^{24}$ y la posibilidad de elección de cada individuo implican el respeto a esa diversidad cultural. Esto es, que los sujetos indígenas puedan contar también con una gama de posibilidades que le son inherentes a su ethos cultural, valores y creencias propias que construyen su mundo posible, que da sentido de pertenencia y posibilidad de ser y estar en el mundo. Esto es, garantizar sus derechos a pertenecer a comunidades culturales diferentes. ${ }^{25}$ 
Diego Valadés (2002: 103) también nos dice que el no asumir la diferencia y valorar la igualdad como contrapuesta a la diferencia es una forma de encubrimiento de la discriminación. En este sentido, el dilema constitucional estriba no solo en cómo se asume el concepto de igualdad/diferencia en el ordenamiento jurídico, sino también en las formas en cómo han sido incluidos o no los pueblos indígenas en ese ordenamiento jurídico; esto es, si son sujetos de derecho como pueblos y comunidades y si adquieren o no personalidad jurídica como entes de derecho público, como ya he mencionado. Y ¿cómo se genera o no una política pública que modifique las formas de ver y pensar a los sujetos indígenas en la sociedad en general y en específico en el sector de impartición y procuración de justicia?

\section{FUNCIÓN QUE TIENE O DEBIERA TENER EL PERITAJE LLAMADO ANTROPOLÓGICO O CULTURAL $^{26}$}

A partir de exponer el lugar y correlación de fuerzas de los pueblos indígenas con respecto al Estado y la sociedad, esperamos quede claro el lugar de vulnerabilidad y de asimetría socioeconómica, política y jurídica de este sector social, que aún hoy tiene. ${ }^{27}$ El observar que la introducción de un nuevo tipo de peritaje en 1991 y que a la fecha no ha sido reconsiderada su reformulación a partir de las modificaciones constitucionales de 1992 y de 2001 en materia de pueblos indígenas, está inscrito en esta dinámica sociopolítica de desigualdad.

Desde 1991, tenemos la posibilidad de hacer peritajes ${ }^{28}$ a individuos que pertenecen a algún grupo étnico en nuestro país, como ya mencioné al inicio de este trabajo en el CFPP plantea la inclusión de peritajes para sujetos indígenas. Antes de hablar de este tipo de peritajes, haré algunas consideraciones generales sobre lo que es.

Como sabemos, el peritaje ${ }^{29}$ es un medio de prueba $^{30}$, también se habla de él como un dictamen, lo que importa subrayar es que constituye el saber de una ciencia, de una disciplina, en un medio de prueba en procesos judiciales. ${ }^{31}$ Esto es, se vuelve una vía que le permite al juez establecer la prueba como valoración en la medida que le da elementos o 
razones para formalizar hechos que escapan a la lógica y entendimiento jurídico. El peritaje es una prueba más dentro del Derecho mexicano, de tradición eminentemente escrita, ${ }^{32}$ en donde los documentos cobran relevancia por encima de los actos verbales o de tradición oral.

No obstante que el juez lo considera como un medio de prueba, el dictamen debe verse con validez plena que se genera en el seno de una disciplina que reconoce aquello que emite como un saber propio de su disciplina. En este sentido se habla del peritaje como un medio de prueba aplicado al campo del Derecho, en procesos judiciales penales. Sin embargo, el peritaje no se reduce o se circunscribe sólo a ese ámbito, también es utilizado en procesos agrarios, civiles, entre otros.

El peritaje no debe pretender sustituir al juez en términos de valorar ni acreditar si el presunto es o no culpable, y este es un punto muy importante para los peritajes en materia antropológica, mismos que veremos más adelante.

El peritaje en general se constituye como una herramienta más que tienen los jueces, los abogados defensores o de la fiscalía, así como lo sujetos implicados para avalar sus argumentos y pruebas en favor o en contra, según sea el caso. Esto quiere decir que el peritaje es un instrumento que requiere de especialistas en otras disciplinas que puedan abonar o probar desde sus especialidades al juez elementos significativos para formular las sentencias.

\section{EL PERITAJE REFERIDO A SUJETOS INDÍGENAS}

Hasta aquí me he referido a los peritajes en general, estos pueden ser muy variados con temas de diversa índole y con la participación de diferentes disciplinas científicas o técnicas que permitan al juez mayor certeza de los hechos en cuestión. El peritaje referido a sujetos indígenas, como ya mencioné, se inscribe de forma específica en $1991 .{ }^{33}$ Sin embargo, hay algunas cuestiones que son importantes poner en la mesa de reflexión y discusión para 
poder entender el lugar específico que puede o tiene nuestra disciplina antropológica y lo que se espera de estos peritajes para individuos indígenas.

En el artículo 220bis del Código Federal de Procedimientos Penales se estipula que «Cuando el inculpado pertenezca a un grupo étnico indígena, se procurará allegarse de dictámenes periciales, a fin de que el juzgador ahonde en el conocimiento de su personalidad y capte su diferencia cultural respecto a la cultura media nacional». ${ }^{34}$

De igual forma, el artículo 220bis es fundamental leerlo con mucha atención debido a que tiene algunos implícitos muy importantes que suelen dejarse fuera de toda discusión y que me parece han llevado a decir que se ha creado abiertamente el peritaje antropológico, como otros aspectos no tan presentes.

Volvamos al artículo 220bis. Podríamos decir que en primera instancia se dieron pasos significativos para incluir en la norma jurídica a los sujetos indígenas y, por ende, la diversidad cultural; por lo tanto, los antropólogos han sido convocados a través de los dictámenes a contribuir en los procesos legales en donde estén involucrados sujetos indígenas, y así fue leída este reforma que permitió la entrada a nuestra disciplina como un saber especializado que puede contribuir a que se den mejores sentencias para sujetos indígenas al tomar en cuenta la diversidad cultural. Si agregamos el artículo 52 fracción $\mathrm{V}^{35}$ que mencionaremos abajo, podríamos decir que en realidad sí estamos hablando de la inclusión de la diversidad cultural en nuestro país, sin embargo no es tanto así.

En realidad, si leemos de nuevo el artículo 220bis no se está hablando de diversidad cultural pero sí de diferencia cultural, y de una diferencia cultural dentro de un horizonte de cultura homogéneo que no reconoce de hecho la existencia de la diversidad cultural, por ende tampoco reconoce los derechos culturales de esos sujetos indígenas. 
Por qué digo esto, porque el mismo texto nos lo enuncia: se quiere conocer la personalidad y que se «...capte su diferencia cultural con respecto a la cultura media nacional». ¿Realmente quiere decir que el aparato jurídico hegemónico está discutiendo y creando una apertura para incluir órdenes legales plurales?, creo que no. Lo que hace es fortalecer una perspectiva cultural hegemónica en donde los sujetos indígenas deben ser medidos a través de esquemas que ponen la centralidad en la cultura nacional, y ésta se encuentra fincada en un horizonte occidental que jerarquiza e inferioriza a sujetos y grupos culturales que no están dentro de su patrones y coherencias preestablecidas y valoradas como positivas.

Los antropólogos debimos y debemos cuestionar qué se quiere decir con la cultura media nacional, ¿cómo se mide?, ¿cómo se establecen los parámetros para medir?, ¿para qué se quiere medir?, ¿a quién sirve esta medición?, ¿qué se quiere lograr con esto?, y si esto sirve realmente para abordar la problemática sobre sujetos y pueblos indígenas en donde ellos se vean reflejados, para que fundamentalmente se garanticen sus derechos humanos.

El artículo 220bis garantiza de hecho algunos derechos de estos sujetos indígenas pero desde una perspectiva que continúa con una inferiorización y un a priori de que son sujetos que no han llegado cabalmente a formar parte de una cultura nacional, están por debajo de la «cultura media nacional», si es que es posible medir y estandarizar la cultura nacional; esto habla más de la incapacidad de su integración y de su situación marginal social, cultural, económica, política y jurídica.

El otro aspecto que está relacionado con lo anterior es, «...allegarse de dictámenes periciales, a fin de que el juzgador ahonde en el conocimiento de su personalidad», más que hablar de estudios antropológicos, está el sesgo o la tendencia hacia estudios sicológicos y más en la lógica criminalística que en la de la diversidad cultural.

En esta misma frase, «... allegarse de dictámenes periciales...», no hay la especificidad del peritaje antropológico, más bien hay la posibilidad de que varios especialistas en «cultura» 
puedan hacer un dictamen pericial, y en ello Augusto Urteaga $(2008)^{36}$ siempre tuvo la claridad de poner sobre la mesa la discusión de este punto.

En el artículo 52 fracción V del Código de Procedimientos Penales para el Distrito Federal en Materia de Fuero Común y para toda la República en Materia Federal se estipula que «El juez fijará las penas y medidas de seguridad que estime justas y procedentes dentro de los límites señalados para cada delito, con base en la gravedad del ilícito y el grado de culpabilidad», así — entre otros, la fracción V— «Cuando el procesado perteneciera a un grupo indígena, se tomarán en cuenta, además, sus usos y costumbres».

En este artículo sí podemos observar que se reconocen «usos y costumbres», entendidos estos como formas de hacer justicia pero sin reconocer que son sistemas normativos, no obstante nos hablan ya de un reconocimiento de formas diferentes de hacer y ver las cosas.

Existen también otros artículos de CFPP relacionados con la especificidad étnica indígena, como son: $124,146,154$ y 223 , en este último se estipula la posibilidad de peritos prácticos. Todos estos artículos, si bien hacen mención a la necesidad de registrar si son o no de algún grupo étnico los individuos indígenas, no hacen referencia clara sobre solicitar peritajes antropológicos que permitan mostrar la diversidad cultural y lo específico de esa cultura que está o no en el o los actos cometidos por el inculpado para tomarse en cuenta, con el fin de una mejor comprensión de los actos llevados a cabo, y a partir de ahí generar una sentencia sobre ese individuo en particular que pertenece a otra cultura diferente a la nacional.

No obstante las deficiencias que podemos encontrar en estos artículos, también podemos ver que se da una apertura a la distinción de sujetos indígenas, y que estos son diferentes o por lo menos se hace necesario reconocer esa diferencia; la ambigüedad de estos artículos hace evidente el vacío conceptual que hay con respecto a la comprensión de la diversidad 
cultural y lo que significa hablar de un Estado pluricultural, también se vislumbra la no disponibilidad de crear una política pública que incluya cabalmente la diversidad cultural.

Tenemos que agregar además los artículos en CFPP que responden a la necesidad de garantizar intérpretes traductores a los sujetos indígenas, ${ }^{37}$ ya que en estos es posible ver con mayor definición el reconocimiento de sujetos con lenguas diferentes, que son portadores de una cultura diferente — aunque lo último no esté cabalmente explicitadoTodos estos artículos hablan de dar garantías a derechos individuales para avalar un debido proceso, pero no para garantizar la inclusión de sujetos culturalmente distintos, tampoco que se generen las periciales correspondientes para mostrar la diversidad cultural, entendida como una diferencia sustancial y no solo como referencia a la cultura hegemónica.

En la introducción mencioné la dificultad que se da en la definición de peritaje referida al ámbito cultural de sujetos indígenas, es decir, como ya he expuesto, no queda claro qué se entiende por diferencia cultural y mucho menos hay claridad para definirlo jurídicamente. Cuándo se debe de solicitarse un peritaje cultural o uno antropológico, cuándo se presupone que los hechos delictivos se han realizado bajo la preponderancia cultural; lo que se debe, entre otras cosas, a la ambigüedad que existe en la comprensión de la diversidad cultural y el reconocimiento jurídico de culturas diferentes, por lo tanto con derechos específicos.

Esta ambigüedad y el desconocimiento real de los operadores de justicia sobre qué es cultura, qué supone la existencia de culturas distintas al interior de un Estado y la poca claridad que existe en la normatividad jurídica sobre lo específico de las periciales, de las periciales antropológicas, así se crea una dificultad en la explicitación de los enunciados que requiere el juez, que los abogados han de despejar para entender los hechos delictivos por un lado, y la especificidad cultural que genera prácticas y acciones concretas en donde se estipula y se establecen categorías sobre lo que es considerado delito, lo que es sancionable jurídicamente o no, etc., entre otras acciones y formas de ver la vida distintas que distinguen a los individuos como parte de una cultura diferente, en nuestro caso, 
mexicano y también latinoamericano, al interior de los Estados nacionales. Esto plantea también un problema práctico y jurídico, ya que a partir de lo que se piensa que es la cultura, el juez y/o el abogado definen sus preguntas para determinar el grado de responsabilidad del indígena sujeto a un proceso.

Hablo ya de peritajes antropológicos porque, a pesar de la no definición jurídica como tal y por tanto su no inclusión, y la dificultad de definición sobre cultura aplicada al ámbito jurídico, es también innegable que se reconoce la existencia de sujetos culturalmente distintos, aunque no se les reconozca plenamente derechos y que se dé, reconocimiento, a partir de confundir estas diferentes culturas con la cultura media nacional.

Es incuestionable también que la Antropología ha sido llamada a intervenir en el ámbito de la justicia. Y es incuestionable también que los antropólogos debemos hacer una reflexión profunda sobre las formas de cómo hemos sido incluidos y la incapacidad como gremio de generar una propuesta de inclusión de los peritajes antropológicos con mayor definición sobre el papel de éstos, con respecto a los sujetos y colectivos indígenas, y la pertinencia de los peritajes antropológicos para este sector social y cuándo no deben hacerse. ${ }^{38}$

Los peritajes realizados desde nuestra disciplina se deben de llamar Peritajes Antropológicos más que Peritajes Culturales, no porque no sea correcta la especificidad, pero ya hemos visto que las implicaciones que tiene la palabra «cultura» abona más a una confusión y a una subordinación de los sujetos indígenas a patrones derivados de la «cultura nacional», por otro lado hablar de peritaje antropológico le da un lugar claro a nuestra disciplina dentro del campo jurídico en el que nos llaman a actuar. ${ }^{39}$

Al establecerse como peritaje disciplinar amplía su margen de acción, pero también requiere mayor esfuerzo conceptual desde la disciplina misma para elaborar claramente los objetivos de los peritajes para sujetos indígenas. Esto permitiría trasformar el artículo 
220bis para que realmente se visibilice y se fortalezca la diversidad cultural, esa diferencia que requiere de la equidad en la diferencia en los procesos jurídicos. ${ }^{40}$

El hablar sobre peritajes antropológicos también implica que los órganos colegiados hagan su trabajo de certificación de peritos, y toda la labor de lobby y de concertaciones con los aparatos de justica para lograr la inserción plena de la disciplina y de sus profesionistas.

FUNCIÓN QUE TIENEN O DEBIERAN TENER LAS CIENCIAS ANTROPOLÓGICAS EN LOS PROCESOS PENALES, EN LOS PERITAJES

Continuamos con el análisis de este inciso, visto preliminarmente en el apartado anterior, y nos preguntamos ¿qué implica la inserción de nuestra disciplina en otro saber disciplinar?, y ¿cuál es la relación que se establece entre ambas y entre los usos y resultados de esta integración de «saberes»?

¿Qué implica el uso de un saber disciplinar para dilucidar una certeza jurídica de un individuo o colectivo caracterizado como diferente?, ¿qué efectos tiene esto?, ¿cuáles son las relaciones sociales y políticas que se fortalecen: la diferencia cultural, la dependencia, la subordinación la interculturalidad, etcétera?

Los peritajes culturales o antropológicos están entrelazados con la investigación antropológica, la acción judicial y las demandas, no solo de los pueblos indígenas sino también de una sociedad que demanda mayor claridad y justicia para todos sus miembros en general. Esto como sabemos no se reduce al ámbito nacional sino también al internacional, el cual cada vez más forma parte de una cultura globlocal que favorece las demandas de sectores vulnerables, como son hasta la fecha los pueblos indígenas en todo el mundo. $^{41}$

Bajo esta dinámica se encuentra inserto el peritaje antropológico, en donde el pluralismo cultural y étnico existente en nuestro país presenta varias dificultades para la impartición de 
justicia en situaciones interculturales, por lo que la búsqueda de un reconocimiento al pluralismo jurídico no debe quedarse en una retórica política sino en una instrumentalización efectiva que se decante en las instituciones y en los procedimientos y normatividades correspondientes. Por ello requiere de un esfuerzo que involucre a los aparatos de justicia, a las comunidades indígenas, y a la sociedad en general, con el fin de aportar a la construcción de una nueva relación que implique, desde luego, el establecimiento de nuevos y mejores canales de entendimiento y nuevos conocimientos que permitan establecer prácticas sociales concretas para la construcción de una mayor equidad jurídica para todos los miembros de la sociedad.

El uso de la pericial antropológica tiene varias dimensiones que deben ser tomadas en cuenta. La primera me parece que es la importancia que tiene para terceros, es decir, para los individuos o colectivos que están sujetos a procesos judiciales y que su situación de libertad o encarcelamiento dependen del uso y del entendimiento que se pueda generar desde el peritaje antropológico para que se incluya no solo la existencia de la diferencia cultural como tal sino también la coherencia y las lógicas que se desprenden de estas culturas, que crean acciones y formas de ver la vida distintas. La otra tiene que ver con el cambio hacia una educación intercultural de los aparatos de justicia y de la sociedad en general, que permita la inclusión plena de la diversidad cultural y, por lo tanto, sea posible generar sentencias que se elaboren desde esta dinámica con el fin de establecer relaciones pares que permitan la equidad, en nuestro caso, en la impartición de justicia.

Por ello, el peritaje puede y debe volverse un instrumento eficaz para la construcción de una nueva relación entre los aparatos de justicia y las comunidades indígenas. Es una y debe ser una práctica científica que cuestione e incida en diálogos interdisciplinarios e intersociales ya que muestra, como dice Esther Sánchez (1992), problemas de comunicación y visión del mundo, donde no solo los sistemas de derecho se contraponen, sino fundamentalmente donde se establece un conflicto de sentido y direccionalidad de formas culturales. Por lo tanto, el peritaje fomenta este acercamiento y establece de manera 
calificada otro conocimiento que define e incide en la toma de decisiones en situaciones de conflicto que trasgreden el sistema sociocultural de la sociedad mayoritaria.

El peritaje antropológico tiene como objetivo primordial aportar vías de entendimiento de aquellos individuos o colectivos que forman parte de culturas diferentes al interior de un Estado; en nuestro caso, estamos hablando de pueblos y comunidades indígenas culturalmente distintos a la llamada sociedad nacional, en situaciones donde los aparatos de procuración e impartición de justicia tienen que generar mecanismos que promuevan un debido proceso a esto sujetos indígenas a través de garantizar su derechos individuales y colectivos; esto implica lograr un sistema donde el pluralismo jurídico sea predominante

\section{PROBLEMAS A DILUCIDAR}

El peritaje antropológico permite evidenciar también la existencia compleja de sistemas jurídicos paralelos pero también imbricados, cuya visión del mundo es juzgada desde el Derecho positivo del referente cultural dominante, haciendo al sujeto infractor o no, culpable o no, sin reconocer las razones que conducen a ese individuo a actuar de acuerdo con sus propias orientaciones trazadas desde su cultura.

El peritaje, entonces, ayuda a dilucidar estas acciones, prácticas y formas de ver y pensar el mundo indígena, que en momentos cruciales, como son los procesos judiciales, se visibiliza - aunque poco- ${ }^{42}$ esa diferencia cultural, esto tiene que ver con el asumir la existencia de una diversidad cultural al interior del Estado, como ya se ha mencionado.

La inclusión del peritaje antropológico es de suma importancia, ya que se espera que continúe destituyendo al peritaje sicológico y/o siquiátrico para evaluar a los indígenas. Estos últimos peritajes son los más solicitados, y en la mayoría de los casos no debían efectuarse. Por un lado, no fortalecen la diferencia cultural, por otro lado son instrumentos que fomentan la sospecha sobre «el otro», privilegiando la visión personal y subjetiva de jueces y abogados los cuales necesitan saber si los individuos indígenas están «bien» de sus 
facultades mentales, si existe un «atraso cultural» ${ }^{43}$ significativo que permita aminorar la pena por estas circunstancias, aunado a las condiciones socioeconómicas. Era muy recurrente utilizar el artículo 59bis de CFPP para sujetos en general que tuvieran una situación socioeconómica y educativa precaria; en este rubro se encuentra la gran mayoría de los sujetos indígenas, o de otra manera escrito: que se mostrara un extremo atraso cultural, un aislamiento social del sujeto con respecto a la media nacional. ${ }^{44}$

$\mathrm{Al}$ fundamentar los jueces sus sanciones a partir de considerar a los indígenas como sujetos sicológicamente inmaduros o retrasados culturalmente no favorecen en realidad a estos individuos, además se promueven prácticas discriminatorias y racistas. Si a esto agregamos que los instrumentos con los cuales se hacen las valoraciones sicológicas o siquiátricas no corresponden a las determinantes culturales de estos sujetos indígenas, tenemos como resultado un sistema de impartición de justicia que pretende serlo, pero en realidad nos deja más dudas que certezas.

El reto y lo específico del peritaje antropológico se encuentra justamente en crear el espacio para que se pueda ver la existencia de mundos posibles diferentes en un sistema que pretende crear un mundo posible en donde todos seamos iguales ante la ley, en donde propone la existencia de grandes universales que permiten la homogeneización de criterios y, por tanto, el establecimiento de una norma jurídica válida para todos los individuos; con lo que se continúa la idea de homogenización cultural y se llevan a cabo reformas que no trasforman las relaciones sociales existentes al no incluir verdaderamente la pluralidad cultural y jurídica en la que vivimos.

Por ello, es necesario definir ${ }^{45}$ ¿cuál o cuáles son los objetivos del peritaje antropológico?

- Mostrar la pertenencia y prácticas culturales diferentes de sujetos individuales y colectivos miembros de pueblos indígenas.

¿Cuál sería la especificidad de este llamado peritaje cultural o antropológico? 
- Mostrar la diferencia cultural en un diálogo intercultural, pues es requerido nuestro saber en un proceso penal, agrario, civil, etc., en donde lo que interesa es dilucidar o dar elementos para llegar a una certeza jurídica que permita al juzgador emitir una sanción individualizada para un sujeto que ya ha sido distinguido como diferente en términos jurídicos.

Esto tiene implicaciones y retos que debemos, como antropólogos, tener en cuenta; requieren de un trabajo en donde es importante saber sobre el grupo etnolingüístico al que pertenece un inculpado y ser concientes de aquellos elementos culturales imbricados y aquellos elementos culturales específicos de dicho pueblo o comunidad indígena, así como conocer los derechos individuales que se reconocen en dichos pueblos o comunidades indígenas para poder escuchar las tensiones y las dificultades que se pueden presentar a la hora de elaborar un dictamen con el fin de tener una mejor perspectiva de las tensiones en las que se encuentra el caso individualizado por resolver.

\section{BALANCES Y PERSPECTIVAS}

¿Qué nos hace diferentes y qué nos hace iguales? Esa es la tensión y esa es nuestra especial intervención, mostrar la diferencia cultural de individuos o colectivos miembros de algún pueblo indígena y aquellos elementos que nos hacen iguales.

Por ello los escenarios en los cuales tendríamos que elaborar nuestros peritajes serían:

- En situaciones generalmente de transición entre las zonas rural y urbana;

- Con indígenas fuera de sus lugares de origen;

- Con indígenas escolarizados que mantienen un vínculo fuerte con sus prácticas y visión del mundo...;

- Con indígenas que por alguna circunstancia marchan de sus poblaciones, mayoritariamente personas monolingües, que aún mantienen un vínculo fuerte con sus lugares de origen; 
- Donde se den procesos de cambio acelerado internos o regionales que afectan o trastocan las relaciones internas. Es decir, en situaciones claras de colisión cultural, jurídica, económica, política, educativa, de género, etc., en donde las relaciones estructurales trastocan las relaciones culturales internas de las comunidades y crean espacios complejos.

Los peritajes antropológicos tendrían que ser capaces de dilucidar. ${ }^{46}$

- Situaciones de colisión de normas jurídicas, en donde las acciones del o de los individuos indígenas no son comprendidas;

- El sistema de derecho propio, como determinante en el caso o no. Esto es, conocer y mostrar las dinámicas de los procesos legales en espacios culturales definidos y distintos;

- La coherencia intrínseca y otras racionalidades que entran en juego en cada caso: brujería, regreso o permanencia de las entidades sagradas, etcétera;

- La pertenencia y calidad de dicha pertenencia a determinada cultura; es decir, ubicar la particularidad del caso y su correspondencia con esa cultura a partir de ubicar a ese individuo en el entramado cultural;

- Los deberes y derechos propios en un determinado marco cultural, y si el individuo actuó bajo esta perspectiva.

$\mathrm{Al}$ estar inscrito nuestro saber disciplinar en otro debemos tener claro los usos y costumbres jurídicas en los cuales nuestros peritajes formarán parte de todo un campo jurídico de hacer justicia, en donde es de suma importancia un diálogo con los operadores de justicia que hayan solicitado el peritaje para lograr un uso lo más efectivo posible donde estos operadores puedan también entender y manejar el dictamen.

Con lo dicho, este diálogo interdisciplinario debe:

- Tener en claro cuál es el hecho u objeto de interés para la justicia; 
- Conocer y entender las cuestiones y disposiciones normativas que el operador de justicia está solicitando que el antropólogo responda, en relación con aquel hecho u objeto;

- Comprender cuál es la relación jurídica que da origen a la demanda;

- Establecer los puntos de pericia con el agente solicitante, de manera que se adecuen al punto de vista antropológico;

- Saber si es necesario hacer un peritaje con otros especialistas de las ciencias antropológicas: como sería un lingüista, un arqueólogo, etnohistoriador, etc.; esto es, llevar a cabo peritajes integrales.

La pertinencia, uso y eficacia del peritaje, están inscritos dentro de todo un proceso jurídico en donde las pruebas pueden mostrar cierta certeza jurídica para el juez con la que llevar a cabo sus sentencias. Estos peritajes, como el antropológico, se encuentran como pruebas poco factibles de ser usadas, por el desconocimiento de los jueces de la diversidad cultural en donde no se reconoce ni la diferencia cultural ni el discurso antropológico, que además es incompresible para profesionistas con otra formación; por ello, uno de los retos y una perspectiva que no se debe perder es la construcción de la verdad jurídica, en donde el saber disciplinar antropológico como tal y la realidad de los sujetos o pueblos indígenas son desconocidos y/o enmarcados en una visión evolucionista de la sociedad. Por ello se habla de atraso cultural y no de diferencia cultural. Así:

- La construcción de la «verdad» en el ámbito de un proceso judicial está limitada por ciertos principios, reglas y prohibiciones, tales como la prohibición de declarar contra sí mismo; la in dubio pro reo — presunción de inocencia—; los límites temporales y requisitos formales exigidos en la producción de las pruebas; el principio de preclusión ${ }^{47}$ procesal; el principio de congruencia. Todos ellos condicionan el razonamiento y valoración judicial de las pruebas;

- De ahí que la «verdad» que se obtiene en la producción de un informe pericial muy rara vez se traducirá plenamente en la resolución judicial. 


\section{CONCLUSIONES}

Los retos desde nuestra disciplina científica se dejan ver, me parece, en varios aspectos, unos teórico metodológicos que involucran la elaboración de conceptos claros, precisos y circunscritos al caso en cuestión; es decir, a sujetos o colectivos indígenas que forman parte de una determinada cultura, y donde las acciones son parte de una determinada representación de ser y hacer que están contenidas en culturas específicas.

Dicho de otra manera, es mostrar la existencia de diferentes mundos posibles, de diferentes sentidos de vida, en donde hay espacios de ininteligibilidad que deben ser reconocidos como tales, y por tanto valorados en esa dimensión, que se caracteriza por una no comprensión donde el diálogo intercultural tiene el desafío de establecer contextos de diálogo lo más horizontales posibles y asumir el reto de no equiparar conocimientos.

Por ello el peritaje antropológico se constituye como una práctica científica que propicia diálogos y explicita las regiones de no contacto cultural, evidencia los problemas de comunicación y visión de mundo donde no solo se contraponen derechos y sanciones sino fundamentalmente se establece un conflicto de sentido y de direccionalidad de formas culturales, claramente diferenciadas pero no asumidas como tales jurídica y socialmente, debido principalmente a su posición de subordinación en donde su condición de culturas diferentes es invisibilizado.

¿Cómo se puede establecer una comunicación intercultural que permita conocer, como menciona Esther Sánchez, dialógicamente a «otros» que son diferentes?, y ¿qué implica aceptar la existencia de mundos posibles diferentes y por tanto formas de conocimientos y significados distintos que no pueden ser codificados o decodificados analógicamente sino a través de aceptar lo distinto y establecer justamente esa distinción entre lo igual, lo similar y lo diferente? (Sánchez 1992). Para el caso mexicano, ¿cómo podemos lidiar con que se capte su diferencia cultural respecto a la cultura media nacional? Algunas posibles respuestas son: 
- Mediante la elaboración de conceptos claros y precisos que muestren la particularidad del caso y su relación con la cultura a la que pertenece el sujeto en cuestión. Mostrar no solo el hecho particular sino también la diferencia cultural y la racionalidad del hecho;

- En contextos complejos habría que distinguir las situaciones derivadas de las relaciones estructurales, las relaciones de imbricación cultural —interna, nacional e incluso internacional-, así como observar la coherencia cultural en estos contextos complejos.

Otro aspecto fundamental tiene que ver con el lugar de nuestra disciplina en la sociedad y la capacidad que tenemos o tengamos para establecer la interlocución con el campo jurídico, también con el campo de creación y gestión de políticas públicas, para que se produzca una mejor inserción de nuestra disciplina.

La capacidad de trabajar colegiadamente y de forma integral entre las distintas áreas de la Antropología y colegios de profesionistas permitirá contribuir e incidir en la procuración e impartición de justicia a sujetos y colectivos indígenas; esto implica:

- Introducir un saber disciplinar en otro saber disciplinar a partir de relaciones asimétricas, en primera instancia, entre los campos científicos del Derecho y el antropológico;

- Explicitar claramente los referentes teóricos, los conceptos y categorías que se usen y el significado que estos tienen en la Antropología para contribuir a un mejor entendimiento de la o las situaciones a dilucidar para evitar confusiones o malos entendidos;

- Establecer un diálogo interdisciplinar con los jueces, abogados y ministerios públicos, para crear un lenguaje y una comprensión de la diversidad cultural, de tal forma que se dé prioridad y se tomen en cuenta los dictámenes periciales antropológicos; 
- Establecer los límites de nuestra participación disciplinar en la construcción de conocimiento sobre las acciones y sentidos de vida de los sujetos indígenas en procesos judiciales;

- Reflexionar sobre la apertura a otros sectores sociales desde el peritaje cultural que no tengan que ver con la diferencia cultural pero sí con individuos o colectivos que pertenecen a la cultura dominante desde la subordinación, desde la contracultura, etc. También reflexionar sobre la apertura a temas como la cultura de la violencia, entre otros. 


\section{BIBLIOGRAFÍA}

Acuerdos de San Andrés Larráinzar, 1996, «Derechos y Cultura Indígena», Secretaría de Gobernación, en http://zedillo.presidencia.gob.mx/pages/chiapas/docs/sanandres.html, [consulta: marzo de 2011].

Bartolomé, Miguel, 1996, Pluralismo cultural y redefinición del estado en México, Departamento de Antropología, Universidad de Brasilia/ CESPE/UNB, Brasil (Serie Antropológica, n. 210).

Carbonell, Miguel, 2001, «Minorías etno-culturales y derechos colectivos: premisas conceptuales», en Derechos humanos. Memoria del IV Congreso Nacional de Derecho Constitucional III, Diego Valadés, IIJ/UNAM, México, pp. 55-70 (Serie Doctrina Jurídica, n. 64).

Clavero, Bartolomé, 1997, «Multiculturalismo y monoconstitucionalismo de la lengua castellana en América», en Derecho Indígena, compilado por Magdalena Gómez, INI/AMNU, México, pp. 65-112.

Código Federal de Procedimientos Penales, 2010, «Capítulo IV: Peritos», en Código Federal de Procedimientos Penales, última reforma 30 de noviembre, en http://www.diputados.gob.mx/LeyesBiblio/ref/cfpp.html [consulta: marzo de 2011].

Código Penal Federal, 2010, «Artículo 51, Fracción V», en Código Penal Federal, última reforma 30 de noviembre, en http://www.diputados.gob.mx/LeyesBiblio/doc/9.doc [consulta: marzo de 2011]. 
Constitución Política de los Estados Unidos Mexicanos, 2010, última reforma publicada DOF 29-07-2010, en http://www.diputados.gob.mx/LeyesBiblio/pdf/1.pdf/ [consulta: agosto de 2010].

Convención Americana sobre Derechos Humanos, 1969, Convención Americana sobre Derechos Humanos San José, Costa Rica, 7 a 22 de noviembre, en http://www.oas.org/juridico/spanish/tratados/b-32.html [consulta: septiembre de 2010].

Convenio 169 OIT, 1989, Convenio 169 sobre pueblos indígenas y tribales, Organización Internacional del Trabajo, en: http://www.ilo.org/public/spanish/region/ampro/ lima/publ/conv-169/convenio.shtml [consulta: julio de 2010].

Couture, Eduardo, 2010, «Principio de Preclusión», en Guía del proceso civil, en www.buenastareas.com/ensayos/Guia-De-Procesal-Civil/617495.html [consulta: agosto de 2010].

Cruz Rueda, Elisa, 2003, «¿Qué quiere decir tener derecho a la cultura?», en Derecho Social. Instrucciones de uso, compilado por Abramovich, M. Añon, Ch. Courtis, Fontamara, México, pp. 297-320 (Doctrina jurídica contemporánea, n. 14).

2007, «Dinámicas jurídicas, construcción del derecho y procesos de disputa en una comunidad indígena de Oaxaca», Tesis de doctorado, Universidad Autónoma Metropolitana Unidad Iztapalapa, México.

Declaración sobre los Derechos de los Pueblos Indígenas, 2007, Declaración de las Naciones Unidas sobre los Derechos de los Pueblos Indígenas, 13 de septiembre, en http://www2.ohchr.org/spanish/issues/indigenous/declaration.html [consulta: septiembre de 2010]. 
Diario Oficial de la Federación, 2001, Reforma al artículo 2o de la Constitución Política de los Estados Unidos Mexicanos, 14 de agosto, en http://www.diputados.gob.mx/ LeyesBiblio/ref/dof/CPEUM_ref_151_14ago01.pdf [consulta: marzo de 2011].

Fabre Zarandoana, Artemia, 1995, «Religión y conflicto social en Oaxaca: Entre el abuso de la autonomía y el ejercicio de la libertad individual», en ¿Persecución religiosa en Oaxaca?, E. Marroquín, Instituto Oaxaqueño de las Culturas/IIS/UABJO, México, pp.123173 (Col. Disha).

1997, «Peritaje antropológico», Diplomado Costumbre, Justicia y Desarrollo en la Tarahumara, 22 de noviembre, ENAH, Chihuahua, México.

1998-1999, «Peritaje antropológico», Diplomado en Antropología Jurídica, Módulo II: Derecho consuetudinario comunitario-Derecho Nacional, Coordinación Nacional de Antropología e Historia-INAH, México.

1999, «El Peritaje Antropológico: ¿Reconocimiento o Borramiento de la Diferencia Cultural?», Diario de Campo, en suplemento n. 3, septiembre, INAH, México, pp. 29-323.

2002-2003, «La interpretación del contexto del delito: el peritaje antropológico cultural forense», en Diplomado en Antropología Forense, Modulo VI: Participación del arqueólogo físico y el antropólogo cultural forense en el área del hallazgo o escena del crimen, $4^{\text {a }}$ Promoción, Coordinación Nacional de Antropología e Historia-INAH, México.

2004-2010, «Presentación del Diplomado», «Introducción al Peritaje Cultural», «Estructura del Peritaje Cultural», «Requisitos y procedimientos, balances y perspectivas», en Diplomado Peritaje en Ciencias Antropológicas, Coordinación Nacional de Antropología e Historia-INAH (primera a sexta promoción), México. 
2005, «Libertad religiosa y colisión de sistemas jurídicos. Los pueblos indígenas y el Estado mexicano», Tesis de doctorado, Universidad Autónoma Metropolitana Unidad Iztapalapa, México.

Fabre Zarandoana, Artemia y Elisa Cruz Rueda, 2008, «El derecho de los pueblos indígenas en la Constitución mexicana ante la incursión y proselitismo religioso», en VI Congreso de la Red latinoamericana de Antropología Jurídica, 28 a 31 de octubre, Bogotá, Colombia.

Ferrajoli, Luigi, 2002, Derechos y garantías. Ley del más débil, $3^{\mathrm{a}}$ ed., Trotta, Madrid, (Col. Estructuras y Procesos. Serie: Derecho).

Gómez Rivera, Magdalena, 1997, «Derecho Indígena y constitucionalidad: el caso mexicano», en Derecho Indígena, coordinado por Gómez, Magdalena, Instituto Nacional Indigenista/Asociación Mexicana para las Naciones Unidas, México, pp. 273- 303.

1998-99, «Derecho Indígena y derecho nacional», Revista de la Universidad de Guadalajara, n. 13, en http://www.cge,udg,mx/revistaudg/rug13/portada.html [consulta: marzo de 2005].

González Galván, Alberto, 2002, Constitución y derechos indígenas, UNAM, México.

Kymlick, 1996, Ciudadanía multicultural: Una teoría liberal de los derechos de las minorías, Paidós, España.

Ley Federal para Prevenir y Eliminar la Discriminación, 2003, en: http://www.diputados.gob.mx/LeyesBiblio/pdf/262.pdf [consulta: marzo de 2010]. 
Ley Federal para Prevenir y Sancionar la Tortura, 1981, en http://www.diputados.gob.mx/ LeyesBiblio/pdf/129.pdf [consulta: marzo de 2010].

López Bárcenas, Francisco, Guadalupe Espinoza et al. (eds.), 2002, Los derechos indígenas y la reforma constitucional en México, $2^{\mathrm{a}}$ ed., Ce.Acatl/Redes/Casa Vieja/COAPI, México.

Monsiváis Márquez, Salvador, 1998, El peritaje antropológico. Juicios y nociones elementales para uso y elaboración, INI, México.

Olivé, León, 1999, Multiculturalismo y pluralismo, Paidós/UNAM-Facultad de Filosofía y Letras, México (Biblioteca Iberoamericana de Ensayos, n. 6).

Organización de los Estados Americanos, s. f., Grupo de Trabajo Encargado de Elaborar el Proyecto de Declaración Americana sobre los Derechos de los Pueblos Indígenas, en http://www.oas.org/consejo/CAJP/Indigenous.asp [consulta: septiembre de 2010].

Ortiz, Héctor, 1998, «El peritaje antropológico: Aspectos Generales» (mimeo).

Pace, Enzo, 1997, «Religiâo e globalizaçâo», en Globalizaço e religiâo, organizado por Oro, Ari Pedro e Carlos Alberto Steil, Vozes, Brasil, pp. 25-42.

Pacto Internacional de derechos Civiles y Políticos, 1966, Adoptado y abierto a la firma, ratificación y adhesión por la Asamblea General en su resolución 2200 A (XXI), de 16 de diciembre, en http://www2.ohchr.org/spanish/law/ccpr.html [consulta: septiembre de 2010].

Pérez Portilla, Karla, 2001, «Aproximaciones al concepto de "minoría"», en Derechos humanos. Memoria del IV Congreso Nacional de Derecho Constitucional III, Diego Valadés, IIJ/UNAM, México, pp. 245-264 (Serie Doctrina Jurídica, n. 64). 
Salmerón, Fernando, 1998, Diversidad cultural y tolerancia, Paidós/UNAM-Facultad de Filosofía y Letras, México (Col. Biblioteca Iberoamericana de Ensayos, n. 1).

Sánchez Botero, Esther, 1992, «Peritazgo Antropológico. Una forma de conocimiento», El otro derecho, n. 2, ILSA, Santa Fe de Bogotá, pp. 18-25.

1996, Seminarios impartidos en Colombia, en Diplomado Binacional sobre cuestiones indígenas e impartición de Justicia, en Sibundoy, Putumayo, Colombia.

1997, Seminarios impartidos en México, en el INI, CIESAS, México.

1998, «Bases Epistemológicas para el análisis de las justicias indígenas» (mimeo), publicado posteriormente en Justicia y pueblos indígenas de Colombia, UNC/UNIJUS, Colombia.

2010, El peritaje antropológico. Justicia en clave cultural, GTZ, Fiscalía y Embajada RFA, Alemania.

Santos, Boaventura de Sousa, 1991, «Una cartografía simbólica de las representaciones sociales: prolegómenos a una concepción posmoderna del derecho», en Estado, Derecho y luchas sociales, ILSA, Colombia, pp. 213-242.

1995, Towards a new common sense. Law, science and politics in the paradigmatic transition, Routledge, New York.

Sartori, Giovanni, 2003, La Sociedad multiétnica. Pluralismo, multiculturalismo, extranjeros e islámicos, Taurus, México. 
Segato, Laura Rita, 1997, «Formacoes de diversidade: nacao e opcoes religiosas no Contexto da globalização», en Globalizaço e religiâo, organizado por Oro, Ari Pedro e Carlos Alberto Steil, Vozes, Brasil, pp. 219-249.

Sierra, María Teresa, 1995, «Articulación jurídica y usos legales entre los nahuas de la sierra norte de Puebla», en Pueblos indígenas ante el derecho, Chenaut, Victoria y Teresa Sierra. CIESAS/Centro Francés de Estudios Mexicanos y Centroamericanos, México, pp.101-123.

Stavenhagen, Rodolfo, 2000, Derechos humanos de los pueblos indígenas, CNDH, México.

Taylor, Charles, 1993, «La política del reconocimiento», en Multiculturalismo y la «política del reconocimiento». Ensayos de Charles Taylor, Amy Gutman, FCE, México, pp. 43-107.

Touraine, Alan, 2002, ¿Podemos vivir juntos?, FCE, México.

Urteaga Castro-Pozos, Augusto, 2008, "El peritaje cultural", en Diplomado peritaje en ciencias antropológicas, noviembre, Coordinación Nacional de Antropología-INAH, México.

Valadés, Diego, 2001, Problemas constitucionales del Estado de derecho, UNAM, México (Serie Estudios Jurídicos, n. 4). 


\section{Notas}

${ }^{1}$ Que más adelante retomaré.

${ }^{2}$ Código Federal de Procedimientos Penales en materia del Fuero Común para el Distrito Federal y para toda la República en materia del Fuero Federal, se puede ver el Capítulo IV: Sobre Peritos, en donde viene todo lo referido a esta especialidad: artículos 220 a 239; más adelante abordaremos los artículos referidos al peritaje en materia indígena, artículo 220bis. En el Código de Procedimientos Penales, nos interesa el artículo 51, fracción $\mathrm{V}$.

${ }^{3}$ Es importante hacer mención que hablar de diversidad cultural o de diferencia cultural no implica necesariamente que estemos defendiendo la imposibilidad de comunicación entre culturas diversas pero sí reconocer que hay espacios de no entendimiento y de dificultad de comunicación debido justamente a que hay elementos que se muestran como ininteligibles o para algunos autores como inconmensurables (Olivé: 147183,1999) y que requiere en principio el reconocimiento de esa situación para lograr los medios de entendimiento y de comunicación posible; justamente en un diálogo intercultural. Muchas veces, se presume el entendimiento y los espacios de imbricación y sincretismo como si no hubiera la existencia de mundos posibles diferentes que se encuentren en un mismo espacio/tiempo y que requiere de ese reconocimiento para dar paso a una relación, como dije, de interculturalidad; el trabajo de Santos (1995, capítulos 1 y 4 principalmente) nos permite observar muy nítidamente la necesidad de cambiar nuestros parámetros sobre el debate, que no debiera ser entre relativismo y universalismo, más bien hablar de «cross cultural process», el cual siempre ha estado pero en una relación desigual. Por ello, en este trabajo se hace énfasis en la diferencia que debe ser tutelada en una relación de equidad.

${ }^{4}$ Magdalena Gómez Rivera en «Derecho indígena y Derecho nacional», Revista de la Universidad de Guadalajara, n. 13, 1998-99, en http://www.cge,udg,mx/revistaudg/rug13/portada.html

${ }^{5}$ Convenio 169 sobre Pueblos Indígenas y Tribales de la Organización Internacional del Trabajo, 1989, entró en vigor en 1991, al que México se suscribió hasta la fecha.

${ }^{6}$ En este trabajo no hacemos especial énfasis en las relaciones de imbricación o uso instrumental de sistemas normativos que los individuos o pueblos indígenas hacen y que hay una bibliografía antropológica amplia al respecto, sino que nos interesa justamente señalar los aspectos que quedan en su mayoría olvidados por esta relación de imbricación o de frontera relacionada con los sistemas normativos y en general de un espectro cultural amplio de apropiación cultural. Me refiero justamente a esos espacios culturales que sí marcan la diferencia y que nos hablan de la existencia de culturas diversas al interior del Estado mexicano y que hacen pertinente por ahora el peritaje antropológico, y de la inserción de nuestra disciplina científica en el saber disciplinar del Derecho. Los trabajos sobre interlegalidad o imbricación legal me parecen buenos ejemplos de la situación aún prevaleciente en México, como los de Santos: «Una cartografía simbólica de las representaciones sociales: prolegómenos a una concepción posmoderna del derecho», 1991, y «Towards a new common sense», 1995; el de MaríaTeresa Sierra, «Articulación jurídica y usos legales entre los nahuas de la sierra norte de Puebla», 1995, y la tesis de doctorado Elisa Cruz Rueda: «Dinámicas jurídicas, construcción del derecho y proceso de disputa en una comunidad indígena de Oaxaca, 2007; mismos buenos representantes sobre estos temas de frontera pero también sobre los procesos de diferenciación de niveles e interlegalidad.

${ }^{7}$ Este inciso retoma partes desarrolladas en mi tesis de doctorado, capítulos 2 y 4, Fabre 2005.

${ }^{8}$ Es en la Constitución de 1857, donde se da el golpe mayor a los pueblos y comunidades indígenas con la Ley de desamortización de los bienes de la iglesia y comunidades indígenas, y en términos culturales será posterior a la Revolución de 1910 y con la Constitución de 1917, que se construye una ideología integracionista y se habla de la necesidad de la unidad nacional vía el proceso de homogeneización para la creación del Estado moderno. Ello implicó, como nos dice Miguel Bartolomé, la represión de la pluralidad cultural, la castellanización forzada, establecer nacionalmente un proyecto de aculturación que representaba el símbolo de la identidad nacional. (Bartolomé 1996: 5). Es hasta la reforma de 1991 y la última de 2001 en donde se asume un reconocimiento político sobre la diversidad cultural, sobre los pueblos originarios de México, se puede ver la propia Constitución Mexicana y el Diario Oficial de la Federación, Reforma al artículo 2. 
${ }^{9}$ Esta adición se sustituyó por la reforma al artículo 2 constitucional. Es pertinente conocer el análisis sobre esta adición al 4 constitucional en el artículo de Gómez, Magdalena, «Derecho Indígena y constitucionalidad: el caso mexicano», 1997, pp. 273-303.

${ }^{10}$ Se publicó la segunda reforma en materia indígena el 14 de agosto de 2001 en el Diario Oficial de la Federación un decreto que adicionó a la Constitución Política de los Estados Unidos Mexicanos un segundo y tercer párrafos al artículo primero, reformó su artículo 2, derogó el primer párrafo del artículo 4, adicionó un sexto párrafo al artículo 18 y otro a la fracción tercera del artículo 115. Puede consultarse, la Constitución mexicana, así como, libros, entre otros: López Bárcenas, Guadalupe Espinoza et al., 2002; artículos periodísticos, revistas especializadas. Ver también: Constitución Política de los Estados Unidos Mexicanos.

${ }^{11}$ Derecho Público es aquel del Estado mexicano, es la relación del Estado como tal en su regulación. En donde una entidad de Derecho público tiene una posición mayor que la de comunidad, implica autonomía, desarrollo y justicia, por ello otorgar a los pueblos indígenas esta categoría de entidad pública requeriría cambios profundos del Estado nacional mexicano a un plural, sería necesario una reforma del Estado. Habría que decir, desde luego, que esta aceptación como entidades de Derecho público requeriría crear jurisdicciones y competencias que hoy, todavía, requieren de reflexión; para ello, se puede ver el trabajo de Villoro (1999: 79-108, principalmente).

${ }^{12}$ Otros sectores como los homosexuales carecen no solo de derechos sino que también son sujetos a la discriminación y violencia.

13 «Esta democracia, a la que puede llamarse cultura, se opone a las concepciones anteriores de la democracia en el hecho de que no recurren a una filosofía histórica sino a una filosofía moral, y tampoco a una filosofía del porvenir...» (Touraine 2002: 257). Esto es, trasformar las ideas liberales de igualdad y libertad por los de equidad. Es decir, dar cabida a otros derechos, a derechos culturales que permitan tener representatividad de grupos e individuos, en este caso a los pueblos indígenas en una relación de interdependencia y no de subordinación y homogenización.

${ }^{14}$ Primera generación: derechos inalienables de todo individuo; es la generación de los derechos civiles y políticos, se reconocen estos derechos por tomar la forma de libertades más que de derechos, debido a que están a favor de la abstención más que de la intervención de los gobiernos para garantizar la dignidad y libertad humana contenidos. Segunda generación: derechos económicos, sociales y culturales, que se ubican más en la perspectiva de derechos en donde la intervención de los Estados es necesaria para garantizar la participación equitativa en la producción y distribución de los bienes. Surgen como respuesta más social y económica para garantizar el pleno desarrollo; son reclamos básicamente para demandar igualdad social. Tercera generación: usualmente no se encuentran plasmados en tratados internacionales, estos apoyan a reclamos de grupos sobre tierra, prácticas culturales, el uso de su lengua y autodeterminación, generalmente se encuentran en estos grupos los pueblos indígenas, las minorías étnicas. Se conocen como los derechos a la solidaridad y están interconectados con los dos primeros. Estos derechos son una demanda por derechos colectivos, aunque cada una manifiesta una dimensión individual y colectiva de todos los países y todas las personas. Son todavía más una aspiración que una realidad legal, ya que mantienen un estatus ambiguo en las normas internacionales de los DDHH. (http://www.Encyclopaedia Britannica Online, «Human Rights», consulta en el año 2004, entre julio y septiembre).

${ }^{15}$ Derechos colectivos: tienen que ver con el reconocimiento de aspectos del orden político, económico y jurídico, de culturas diferentes. En este sentido, derecho a la cultura entendida ésta como derecho a la identidad cultural propia y no como derecho al acceso a la cultura en sentido genérico (de Lucas 2003). Derecho a la cultura es una reclamación política de pueblos y minorías que tiene ya un aval no solo desde Unesco, en varias de las Declaraciones, específicamente la Declaración de las Naciones Unidas para Pueblos Indígenas, también la Organización Internacional del Trabajo a través del convenio 169 sobre pueblos indígenas y tribales desde 1989, y actualmente la Organización de Estados Americanos trabaja sobre una declaración donde se pugna por el reconocimiento de los derechos colectivos. Estos reconocimiento se han impulsado desde diferentes frentes de sectores académicos — desde la ciencia jurídica y las ciencias sociales, en general-, civiles, desde los mismos sectores interesados y desde las esferas internacionales y nacionales donde se reclama por sociedades plurales. 
${ }^{16}$ Otra postura es la propuesta en los Acuerdos de San Andrés de febrero de 1996 entre el Ejército Zapatista y el gobierno federal, como un proceso de negociación y acercamiento sobre el reconocimiento de derechos en el marco del Estado.

${ }^{17}$ La relación y situación de los Estados nacionales ha cambiado y es necesario establecer adecuaciones; debido al debilitamiento de los Estados, y como consecuencia de esto se ha dado también la posibilidad de establecer reivindicaciones de grupos y pueblos diferentes que forman parte de estos Estados nacionales en todo el mundo, donde las correlaciones de fuerza y lugares de los sectores sociales se han estado modificando pero siempre bajo una relación de supeditación al Estado a pesar de su llamado debilitamiento o achicamiento(ver capítulo 2, Fabre 2005).

${ }^{18} \mathrm{La}$ autonomía, como reconocimiento de derechos colectivos, tiende a apuntar hacia la «especificación de derechos», que es un proceso normal dentro del constitucionalismo contemporáneo más que hacia la destrucción de los tradicionales derechos de libertad e igualdad, como nos dice Miguel Carbonell (2001: 5570), también ver Javier de Lucas (2003: 297-320).

${ }^{19}$ De ahí las bizarras discusiones sobre el debilitamiento y quiebre de la soberanía nacional si se otorgan derechos públicos, derechos culturales a los pueblos indígenas, pues ello conlleva derechos a la autonomía y a la autodeterminación de dichos pueblos. Asimismo, se dice, se violan los derechos individuales, fundamento pilar en la construcción de los Estados nacionales y del constitucionalismo contemporáneo. No obstante los argumentos y temores, existe hoy una amplia bibliografía que aborda estos temas desde la perspectiva de las ciencia política, jurídica, filosófica, antropológica y desde los derechos humanos, etc., que demuestran no solo la viabilidad y necesidad de las adecuaciones constitucionales hacia la pluralidad cultural, para construir diálogos interculturales al interior de los países como fuera de ellos, en términos de la interculturalidad que permita dirimir conflictos y buscar soluciones conjuntas; en el entendido justamente de un diálogo que pueda acotar y establecer marcos de referencia para el diálogo. Siempre y cuando se dé una premisa previa, lograr el establecimiento de relaciones de pares - lo más que se pueda - a partir de establecer acciones afirmativas, para este diálogo intercultural y no en la asimetría socioeconómica, política y cultural y la discriminación. Hay una variada bibliografía que se puede consultar, entre ella, Bartolomé 1996; Carbonell 2001; Ferrajoli 2002; González Galván 2002; López Bárcenas et al. 2002; Olivé 1999; Pérez Portilla 2001; Salmerón 1998; Sartori. La Sociedad multiétnica. Pluralismo, multiculturalismo, extranjeros e islámicos, Taurus, 2003; Santos: 1995; Stavenhagen, Derechos humanos de los pueblos indígenas, CNDH, México, 2000.

${ }^{20}$ La retórica jurídico política se debe a que no hay una voluntad política pública que quiera trasformar las relaciones sociales y de poder y, por ende, también en el ámbito jurídico es posible observar sólo reformas que no llevan a procesos de trasformación reales.

${ }^{21}$ Autonomía que también propone parte del Movimiento Indígena en México y que quedó consignada en los Acuerdos de San Andrés Larráizar, autonomía desde las comunidades, y que sea el propio proceso interno el que vaya dictando las pautas para la reagrupación y reasignación de municipios y regiones autónomas en aquellos casos que esto sea posible. En este sentido, vale la pena incluir la propuesta de Charles Taylor, «La política del reconocimiento», en Amy Gutman, Multiculturalismo y la «política del reconocimiento», Ensayos de Charles Taylor, México, FCE, pp. 43-107, ya que nos permite incluir justamente la perspectiva del reconocimiento político y los contextos socioculturales de los pueblos colonizados.

${ }^{22}$ Por ejemplo, los Derechos Humanos Religiosos y los Derechos de los Pueblos indígenas consignados en nuestra Constitución no reflejan ni la equidad ni la inclusión de derechos específicos sobre los derechos religiosos de los pueblos indígenas, lo cual genera situaciones de vulnerabilidad jurídica y social (ver Fabre 2005, Fabre y Cruz 2008).

${ }^{23}$ El problema no solo está en aquellos derechos que los hacen iguales a todo el resto de los mexicanos, en abstracto y tomado en cuenta como Ferrajoli (2002: 70-110) menciona, a un sujeto en abstracto varón, blanco, alfabetizado, etc., que no se finca en su identidad grupal ni individual. Sobre la cultura es lo mismo, se habla en abstracto y al mismo tiempo se asume la cultura occidental, y en particular aquella cultura nacional que se asume igual para todos, violentado las diferencias sociales, económicas, políticas y culturales de esos pueblos.

${ }^{24}$ Aun si los individuos no son indígenas es difícil mantener esta idea de homogenización de valores y creencias, más bien hay una diferenciación socioeconómica y social bastante acentuada que crea valores y 
creencias muy diversos y a veces contrapuestos que hace difícil mantener ese horizonte de homogeneidad; si a esto sumamos la diferencia cultural de sujetos indígenas resulta más evidente la diferencia y la desigualdad en donde los sujetos indígenas quedan invisibilizados y vulnerados en su diferencia cultural justamente por esta idea de igualdad.

${ }^{25} \mathrm{La}$ existencia de culturas diferentes en una nación constituye a unas como dominantes y a otras como dominadas, no importando el número de miembros, lo que las constituye como minorías y como minorías culturales, tema que es de nuestro interés, que por razones históricas, económicas políticas, etc., nos muestra cuáles culturas se encuentran en desventaja de subalternidad o de menor poder respecto a otras en la misma sociedad; como es el caso de los pueblos indígenas, que desde la conquista hasta nuestros días no gozan de iguales oportunidades para ejercer sus derechos ciudadanos. Esto es importante porque nos permite conocer y observar las limitantes que existen respecto a garantizar derechos plenos a los miembros de culturas diferentes en nuestro país, como es el caso de los pueblos indígenas. Los trabajos entre otros como los de Villoro (1999), Carbonell (2001), Ferrajoli (2002), nos permiten colocar mejor la situación y discusión de los pueblos indígenas.

${ }^{26} \mathrm{La}$ base del siguiente apartado está basada en el artículo propio: «¿El Peritaje Antropológico: Reconocimiento o Borramiento de la Diferencia Cultural?», Diario de Campo: Suplemento 3, INAH, México, Septiembre 1999, pp. 29-32, además de las correcciones que hice posteriormente al artículo debido a varias omisiones, aquí retomo también los trabajos realizados para seminarios, cursos, en diferentes Diplomados de Antropología jurídica de CNA/INAH, en diferentes años: 1997, 1998, 1999 y 2000, así como los temas abordados en el Diplomado Peritaje en Ciencias Antropológicas, de CNA/INAH, 2004, 2008, 2009, 2010.

${ }^{27}$ No quiero dejar de reconocer y asumir que los pueblos indígenas en México han tenido y tienen la capacidad de reconstruirse, trasformarse, adecuarse a las circunstancias históricas con gran vitalidad, por ello se ha dado la generación de demandas político jurídicas y económicas que han hecho; por tanto, han contribuido también a la juridización de sus derechos. Sin embargo, las respuestas recibidas no son las esperadas ni las que más garantizan la equidad y la pluralidad.

${ }^{28}$ Ya se habían realizado peritajes antropológicos pero no desde esta dinámica de inclusión en la procuración de justicia, como lo está ahora.

${ }^{29}$ En Fabre 1998.

${ }^{30}$ En el Código Federal de Procedimientos Penales, el artículo 93 habla sobre los peritajes, en el 223 se habla de quién puede ser perito profesional y qué son los peritos prácticos.

${ }^{31}$ Procesos Agrarios, Civiles, etc., lo más frecuente son en procesos penales. Existen distintos tipos de peritajes: médico forense, poligrafía, criminología, identificación de huellas, sicológico, siquiátrico, de tránsito terrestre y aéreo, en ingenierías, balístico, antropológico, etcétera.

${ }^{32}$ Actualmente hay juicios orales que forman parte también de esta lógica jurídica en donde quedan formalizados a través de la escritura de dicho proceso, aunque eso puede considerarse un avance de este derecho.

${ }^{33}$ Anteriormente ya se habían realizado peritajes antropológicos, lo que presenta una diferencia significativa es la mención de sujetos indígenas pertenecientes a algún grupo indígena, que ocasiona la entrada muy clara de peritajes antropológicos en los procesos penales.

${ }^{34}$ Existen también otros artículos de CFPP relacionados con la especificidad étnica indígena, como son: 124, 146, 223, en este último se estipula la posibilidad de peritos prácticos. Es importante poner atención que en el artículo 220bis ya que se establece claramente la relación entre lo indígena y la nación, ello implica una reflexión sobre la pertinencia o no del peritaje y sus limitaciones, debido a la visión etnocéntrica de dicho artículo.

${ }^{35}$ Este habla de tomar en cuenta los usos y costumbres, ver más abajo.

${ }^{36}$ Augusto Urteaga, en las sesiones del Diplomado en Peritaje en Ciencias Antropológicas del INAH, en específico la de noviembre de 2008, «El peritaje cultural», hace una reflexión semejante a la propia, sobre lo que implica hablar de peritajes culturales y no en específico de peritajes antropológicos, ya que cualquier experto en cultura puede entonces ser llamado a llevar a cabo estos peritajes. Esta reflexión nos llevó a ambos 
a discutir e insistir en que sea nombrado el peritaje antropológico como tal en el CFPP, lo cual permitiría la inclusión de las ciencias antropológicas como disciplina.

${ }^{37}$ Los artículos que hacen mención en CFPP a la especificidad lingüística son los siguientes: 28, 29, 30, 103, 124bis, 128, 246 fracción IV, 246, 388; en la Constitución Política de los Estados Unidos Mexicanos, artículo 2, A, VII; así como en el 169 de la OIT; en la Convención Americana sobre Derechos Humanos; Pacto Internacional de derechos Civiles y Políticos; Ley Federal para Prevenir y Eliminar la Discriminación, Ley Federal para Prevenir y Sancionar la Tortura.

${ }^{38}$ Esta poca claridad llevó a generar dictámenes de identidad y aceptar prácticamente cualquier solicitud, por ello es necesario acotar nuestra intervención para que realmente sea edificante, y porque la Antropología como disciplina científica puede y será llamada a llevar a cabo otro tipo de peritajes, como ya se están haciendo en materia de procuración de justicia con perspectiva de género para víctimas de violencia, donde la Antropología está siendo convocada.

${ }^{39}$ El hablar de peritajes antropológicos nos ahorra también el discutir y hablar sobre la existencia de peritajes normativos y peritajes culturales, como si no pudiéramos desde nuestra disciplina esclarecer a otros, lo que significa hablar de cultura, culturas diferentes y de diversidad cultural en donde la distinción de peritajes normativos profundiza más el desconocimiento sobre la diversidad cultural y el lugar que ocupan los sistemas normativos al interior de culturas específicas; es apuntar o profundizar la parcialización de las culturas indígenas. Por ello, me parece fundamental sólo hablar de peritaje antropológico, y es en la especificidad de cada caso que se definirá el tipo de peritaje antropológico que se requiera. Actualmente en procuración de justicia se están llevando a cabo peritajes antropológicos en trata de blancas y menores; se está utilizando cada vez más en otras problemáticas sociales, fuera del ámbito de los pueblos indígenas.

${ }^{40}$ No solo en los procesos jurídicos sino también en todo ámbito social que requiera garantizar derechos individuales a sujetos pertenecientes a otras culturas.

${ }^{41}$ Pace 1997, Segato 1997.

${ }^{42}$ Digo que se evidencia - aunque poco - porque si bien es evidente la diferencia de sujetos indígenas frente a aquellos que no lo son, se invisibiliza en el mismo proceso debido a que los instrumentos que se utilizan desde el ministerio público van encubriendo la diversidad cultural, a tal grado que muchas veces o en su mayoría no se llaman a intérpretes traductores desde la primera declaración. Esta situación se va agudizando en todo el proceso y sólo queda la necesidad de probar el atraso cultural y económico pero no la diferencia cultural que los hace diferentes, por lo que sus derechos son violados en todo el proceso.

${ }^{43}$ Con respecto a la cultura media nacional, además de llevar a cabo exámenes sicológicos se agrega el nivel educativo como prueba de su ignorancia de la cultura nacional, sin averiguar o conocer el conocimiento real y efectivo que tiene dentro de su propia cultura.

${ }^{44}$ No obstante que se usa el término media nacional no queda claro a qué se refiere ni mucho menos cómo medir o crear patrones de referencia.

${ }^{45}$ En este ensayo solo haremos mención, en este apartado, sobre algunos de los temas fundamentales que es necesario seguir profundizando en casos específicos y que esperamos que en un trabajo posterior sea posible presentar; así como reflexionar también sobre las metodologías y procedimientos que se requieren para la presentación formal del dictamen antropológico para su uso en el ámbito de la justicia. Puede consultarse, por ahora, el libro de Sánchez Botero 2010, para el caso colombiano, en donde la autora nos va dando casos específicos sobre estas problemáticas.

${ }^{46}$ Para mayor profundidad de estos señalamientos consultar los trabajos de Esther Sánchez 1997, 2010.

${ }^{47}$ La preclusión se define, según Couture, «como la pérdida, extinción o consumación de una facultad procesal». Esta puede resultar de tres situaciones diferentes: «a) por no haber observado el orden u oportunidad dado por la ley para la realización de un acto; b) por haberse cumplido una actividad incompatible con el ejercicio de otra; c) por haberse ejercido ya una vez, válidamente, esa facultad — consumación propiamente dicha—. También por 1. Imposibilidad de iniciar o continuar el ejercicio de la acción penal; 2. Existencia de una causal que excluya la responsabilidad, de acuerdo con el Código Penal; 3. Inexistencia del hecho investigado; 4. Atipicidad del hecho investigado; 5. Ausencia de intervención del imputado en el hecho investigado; 6. Imposibilidad de desvirtuar la presunción de inocencia; 7. Vencimiento 


del término máximo previsto por la ley. Guía del proceso civil, en
http://www.buenastareas.com/ensayos/Guia-De-Procesal-Civil/617495.html [consulta: agosto de 2010].

Fecha de recepción: 10 de diciembre de 2009.

Fecha de aceptación: 7 de septiembre de 2010. 